\title{
The TanDEM-X Change DEM: the new temporal DEM of the Tan- DEM-X Mission
}

Marie Lachaise, Markus Bachmann, Thomas Fritz, Martin Huber, Barbara Schweißhelm, Birgit Wessel

German Aerospace Center (DLR), Münchener Str. 20, 82234 Oberpfaffenhofen, Germany

\begin{abstract}
The TanDEM-X mission is currently acquiring a new dataset to provide a temporally independent DEM, the so-called “TanDEM-X Change DEM". This set of acquisitions taken between 2017 and 2020 has a clear temporal separation with respect to the data used for the generation of the TanDEM-X global DEM which were acquired between 2010 and 2015. Therefore, this new DEM aims to enable the characterization of terrain changes. Improvements in the acquisition planning process and in the data processing have been necessary to allow the generation of this Change DEM with fewer acquisitions but still very high accuracy. For this, the use of an edited TanDEM-X DEM as a "starting point" for the interferometric processing is mandatory.
\end{abstract}

\section{Introduction}

Since 2010, the TanDEM-X mission flies two similar satellites as a large single-pass bistatic SAR interferometer. The acquisition for the global TanDEM-X DEM took place until 2015 and the product was completed in 2016. This global TanDEM-X DEM raised great interest. However, part of the data used for its generation is already more than eight years old and many changes in the topography of the Earth occurred since then. Consequently, in 2017, the TanDEM-X mission decided to acquire an additional complete coverage of the Earth's landmass as the satellites have sufficient resources for several more years of operation [1]. The goal is to provide a temporally independent dataset within a well-defined time span from September 2017 to mid 2020. This additional DEM will allow monitoring topographic changes on a global scale by comparing it to the TanDEM-X DEM. The name of the resulting product is therefore "TanDEM-X Change DEM".

This paper summarizes the concepts for the new acquisitions and the specifications of the TanDEM-X Change DEM. It then outlines the different steps of its generation and finally presents some first results.

\section{TanDEM-X Change DEM}

\subsection{Acquisitions}

For the global TanDEM-X DEM, at least two global coverages were performed and two more coverages were acquired over mountainous terrain from an opposite viewing direction in order to resolve shadow and layover. Additionally, individual regions like deserts and forests were re-acquired in specific configurations. All in all, it took around four years to collect all the data. In order to reduce the acquisition duration and due to additional constraints, the acquisition planning has been improved. Such constraints are the shorter maximal duration of a data take to avoid too fast degradation of the battery and the lower number of ground stations restraining dramatically the contact time per orbit. The newly elaborated acquisition scenario maximizes the performance based on the experience and lessons learned from the TanDEM-X global DEM acquisitions. The Earth was separated into dedicated acquisition areas according to the dominant land classes, terrain types and seasonal changes as shown in Figure 1.

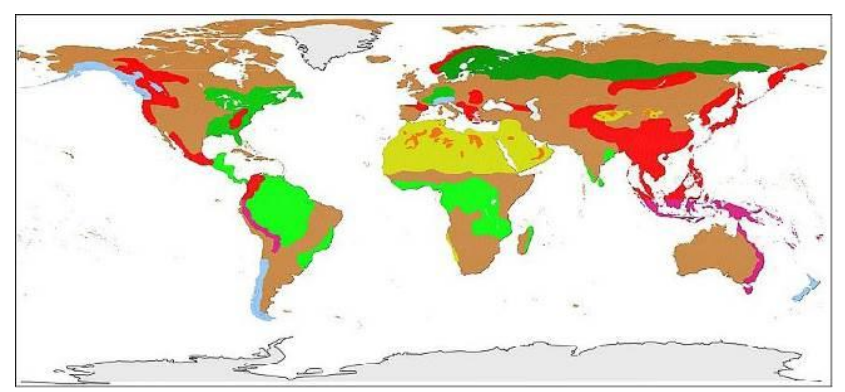

Figure 1 Areas covered during the TanDEM-X Change DEM acquisition phase (from 2017-09-21 until 2019-12-31)

Most of the Polar Regions (grey) were already acquired in the respective local winter seasons of 2016/2017. Glaciers (light blue) are acquired twice during local winter in order to avoid low coherence of melted ice and snow. Mountains and mountainous forests (red/pink areas) are acquired twice in local summer time to reduce noise and to get additional information for processing. Moreover, glaciers, mountains or mountainous forests need be acquired with heights of ambiguity (HoAs) between $45 \mathrm{~m}$ and 90 $\mathrm{m}$. Mountainous deserts (orange) are acquired twice independently of the season. Temperate and boreal forests (dark green) are acquired once in local summer ("leaf on"). Deserts (yellow) are acquired with steep incidence angles to compensate for the low backscatter of sand and thus to ensure a sufficiently high signal-to-noise ratio. Finally, tropical forests (light green) and the rest of the world (brown) are acquired once independently of season but with HoAs larger than $50 \mathrm{~m}$ for forest. Table 1 summarizes the acquisition constraints for each acquisition region indicated by the same color as in Figure 1. 


\begin{tabular}{|c|c|c|c|c|c|}
\hline Region & $\begin{array}{l}\text { Cov } \\
\text { era } \\
\text { ges } \\
\end{array}$ & Season & $\begin{array}{l}\text { Height of } \\
\text { Ambiguity }\end{array}$ & $\begin{array}{c}\text { Incidence } \\
\text { Angle } \\
\text { Range } \\
\end{array}$ & $\begin{array}{c}\text { Expected } \\
\text { Relative } \\
\text { Height Error } \\
\end{array}$ \\
\hline $\begin{array}{l}\text { Mountains } \\
\text { with } \\
\text { forest }\end{array}$ & 2 & $\begin{array}{l}\text { Local } \\
\text { summer }\end{array}$ & $\begin{array}{l}55 m-75 m\left(1^{\text {st }}\right) \\
45 m-53 m\left(2^{\text {nd }}\right)\end{array}$ & $27-49 \mathrm{deg}$ & $2 m-4 m$ \\
\hline Glaciers & 2 & $\begin{array}{l}\text { Local } \\
\text { winter }\end{array}$ & $\begin{array}{l}55 m-75 m(1 \text { st }) \\
45 m-53 m\left(2^{n d}\right)\end{array}$ & $29-47 \mathrm{deg}$ & $2 m-3 m$ \\
\hline $\begin{array}{l}\text { Tropical } \\
\text { forest }\end{array}$ & 1 & $\begin{array}{l}\text { Year } \\
\text { round }\end{array}$ & $50 m-60 m$ & $27-49$ deg & $2.5 m-4.5 m$ \\
\hline $\begin{array}{c}\text { Temperate } \\
\text { and boreal } \\
\text { forest }\end{array}$ & 1 & $\begin{array}{l}\text { Local } \\
\text { summer }\end{array}$ & $50 m-55 m$ & $27-49$ deg & $2.5 m-4 m$ \\
\hline $\begin{array}{c}\text { Deserts } \\
\text { with } \\
\text { mountains }\end{array}$ & 2 & $\begin{array}{l}\text { Year } \\
\text { round }\end{array}$ & $\begin{array}{l}55 m-75 m\left(1^{\text {st }}\right) \\
45 m-55 m\left(2^{\text {nd }}\right)\end{array}$ & $27-49$ deg & $3 m-7 m$ \\
\hline Deserts & 1 & $\begin{array}{l}\text { Year } \\
\text { round }\end{array}$ & $23 m-45 m$ & $14-38$ deg & $2.5 m-5 m$ \\
\hline $\begin{array}{l}\text { Rest of the } \\
\text { world }\end{array}$ & 1 & $\begin{array}{l}\text { Year } \\
\text { round }\end{array}$ & $35 m-45 m$ & $27-49$ deg & $1 \mathrm{~m}-2.5 \mathrm{~m}$ \\
\hline
\end{tabular}

Table 1 Acquisitions parameters and expected relative height error for the Change DEM acquisitions

During the acquisition of the Change DEM dataset, the system faced two further challenges. First, the number of conflicts with commercial and scientific customers increased due to higher utilization of the satellites for acquiring TerraSAR-X mission products. An agreement with the commercial partner Airbus D\&S was therefore established. Second, in July 2019 the primary transmit chain on TDX-1 failed due to a malfunction of the first high power amplifier stage. The redundant chain was switched on and the TanDEM-X mission was re-activated after about two months. Both challenges mentioned above lead to a prolongation of the acquisition phase from end of 2019 into the first half of 2020 . Currently, about $85 \%$ of the data for the Change DEM is acquired.

\subsection{Specification}

The Change DEM follows technically the same product format specifications as the final global TanDEM-X DEM [2]. It has $12 \mathrm{~m}$ posting and is expected to have similar absolute horizontal and vertical accuracies (see Table 2). The absolute height accuracy which is driving the use for temporal height change detection will be in the same order as the TanDEM-X global DEM, respectively, well below 10 meters [3].

\begin{tabular}{|c|c|c|c|c|c|}
\hline DEM Product & Posting & $\begin{array}{c}\text { Absolute } \\
\text { Horizontal } \\
\text { Accuracy } \\
\text { CE90 }\end{array}$ & $\begin{array}{c}\text { Absolute } \\
\text { Vertical } \\
\text { Accuracy } \\
\text { LE90 }\end{array}$ & $\begin{array}{l}\text { Relative Vertical } \\
\text { Accuracy } \\
90 \% \text { linear } \\
\text { point-to-point } \\
\text { error }\end{array}$ & Coverage \\
\hline $\begin{array}{c}\text { TanDEM-X DEM } \\
\text { (standard product) }\end{array}$ & $\begin{array}{l}0.4 \mathrm{arcsec} \\
(\sim 12 \mathrm{~m} @ \\
\text { equator })\end{array}$ & $\begin{array}{l}\text { Specified: }<10 \mathrm{~m} \\
\text { Measured: }<2 \mathrm{~m}\end{array}$ & $\begin{array}{c}<10 \mathrm{~m} \\
\text { Measured: }<2 \mathrm{~m}\end{array}$ & $\begin{array}{l}2 \mathrm{~m} \text { (slope } \leq 20 \%) \\
4 \mathrm{~m} \text { (slope }>20 \% \text { ) }\end{array}$ & Global \\
\hline $\begin{array}{l}\text { TanDEM-X Change } \\
\text { DEM (CDEM) } \\
\text { (2nd temporal DEM) }\end{array}$ & $\begin{array}{l}0.4 \mathrm{arcsec} \\
(\sim 12 \mathrm{~m} \otimes \\
\text { equator) }\end{array}$ & $<10 \mathrm{~m}$ & $\begin{array}{l}<10 \mathrm{~m} \\
\text { expected similar } \\
\text { to DEM }(<2 \mathrm{~m})\end{array}$ & Not specified & $\begin{array}{c}\text { Global } \\
\text { acquisitions } \\
\text { (with local gaps.) }\end{array}$ \\
\hline
\end{tabular}

Table 2 TanDEM-X DEM and Change DEM specifications

Nevertheless, there are two major differences:

1. although the acquisitions will be global, the mosaicked final TanDEM-X Change DEM may not be global. There will be data gaps due to missing acquisitions or DEM scenes not suitable for Change DEM mosaicking. These areas may not be re-acquired in the scheduled time span. The corresponding pixels will be marked as invalid.

2. the lack of several coverages will affect the relative height error performance. These random errors will also vary slightly over the swathes (in range) since a clapboard pattern of two coverages with shifted beams is no longer available. Consequently, more filtering (more interferometric looks and different filters) will be applied to minimize the noise. Table 1 gives an overview of the relative height accuracy to expect depending on the different acquisition regions.

Some other known deviations are listed in the following:

- there will be areas with remaining local phase unwrapping errors which may not be resolved in the final Change DEM since there are no independent coverages to average/combine. Large absolute height offsets might thus be present on local scales.

- shadow and layover regions in difficult terrain will not always be filled with data from other viewing geometries.

- other limitations to the information layers (e.g. limited accuracy of the water mask) due to the reduced number of coverages.

\section{Generation of the TanDEM-X Change DEM}

\subsection{Interferometric processing}

Since there will be only one new global coverage, the dual-baseline framework developed for the mission cannot be used anymore. However, the now available final global TanDEM-X DEM product can be used to counter this issue. The Change DEM acquisitions are thus processed by the so-called "delta-phase" approach developed originally for the processing of the High-Resolution DEM acquisitions [4] in the interferometric processor (the ITP) instead of the dual-baseline phase unwrapping algorithm as depicted in Figure 2. Nonetheless, the global DEM cannot be used as is. Editing is required since it is an interferometric surface model which includes noise and artefacts from incoherent areas.

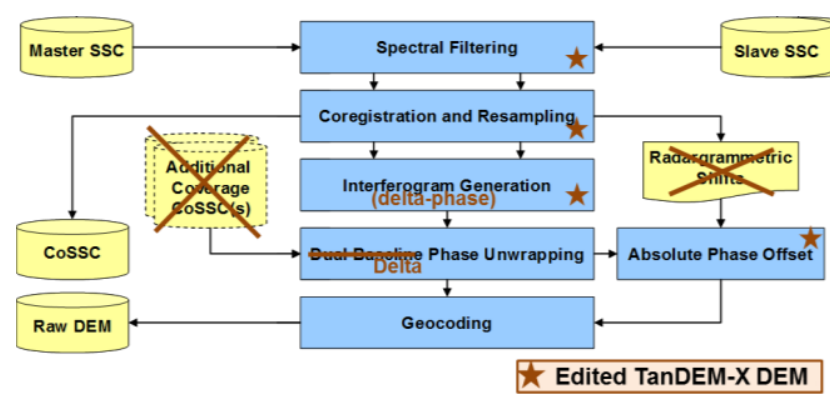

Figure 2 Update of the ITP interferometric part of the ITP to enable the processing of the new acquisitions. 


\subsubsection{TanDEM-X DEM editing}

The global TanDEM-X DEM still contains some small gaps and voids and water bodies are characterized by noise as their height is exclusively derived from the interferometric SAR data. For phase unwrapping, these areas need to obtain valid elevation values. Two frameworks have been developed at DLR in order to edit TanDEM-X DEMs. Both are able to identify and flatten the water bodies, to interpolate void areas and perform edge-preserving smoothing:

- one framework is specific for Antarctic and Greenland. It is semi-automatic and focuses especially on the derivation of the land/ice-shelf water front. It is applied on the $12 \mathrm{~m}$ posting TanDEM-X DEM [5].

- the other one, for the rest of the world, derives and uses reference maps to identify water bodies and fill the voids. It is performed on the $30 \mathrm{~m}$ posting version of the global TanDEM-X DEM [6].

\subsubsection{Interferometric processing}

Instead of the phase equivalent of a flat Earth, the phase simulated from the edited version of the global TanDEM$\mathrm{X}$ DEM is subtracted from the acquired interferometric phase in order to reduce the density and number of the interferometric fringes. It is important to note, that - although the process starts with the first global DEM - the new phase (height) values are independent of the old ones. Phase unwrapping is significantly facilitated and errors are nearly eliminated. Nevertheless, large scale errors in the edited DEM may not be fully recovered by the process despite the moderate HoAs of the new acquisitions and may affect the output DEM performance.

The process also analyzes temporal changes and uses stable areas for calibration of the absolute height (absolute phase offset) of the Change Raw DEMs which is thus no longer based on the stereo-radargrammetric data exploitation. These areas, which show no significant changes, are also used to pre-calibrate the individual (Raw) DEM scenes prior to geocoding. This further reduces possible offsets and horizontal shifts in the data - facilitating greatly final calibration and mosaicking. Hence, the so-called pi-ambiguities (i.e. wrongly selected height ambiguity bands due to synchronization phase offsets) will be avoided. The usage of the edited DEM reduces the overall effort in the processing (no more re-processing due to the pi-ambiguities) and calibration in order to mitigate the loss of freedom in the selection of suitable raw DEM data from the available coverages.

\subsection{Final calibration and mosaicking}

Before mosaicking the absolute calibration of the Change raw DEM scenes is checked by the Mosaicking and Calibration Processor (MCP). The calibration comprises a leastsquares adjustment to ICESat calibration points and tie points to neighbouring DEM scenes like the procedure applied for the global DEM. This will detect inconsistencies in the pre-calibrated Change raw DEM scenes and ensures the same exact vertical accuracy like for TanDEM-X DEM [6]. In contrast to the mosaicking of the TanDEM-X DEM and
HDEM products, that needed a complex selection and combination approach of several coverages, for the Change DEM just a single coverage is fused for most areas. In case of overlapping areas, a height error weighted mean fusion will be applied. The DEM production will concentrate on areas with potential 3D changes.

\section{Demonstration over Devon Island}

The proposed Change DEM generation process was tested in different areas and applied on several short data takes over Devon Island. Figure 3 shows the nominally flattened interferometric phases and the residual phases (so-called "delta-phases"). In Figure $3 b$ the depicted residual phases exhibit few fringes which ease and fasten dramatically phase unwrapping. Nevertheless, there are obvious larger changes in the measured height. Figure $4 \mathrm{c}$ presents these changes in blue, i.e. the glaciers and the snow-covered regions with height differences of down to $-5 \mathrm{~m}$. Due to the independent phase unwrapping, the actual elevations could be maintained. The red boxes in Figure $4 \mathrm{c}$ are the overlapping areas between the two scenes. The height differences there are the nearly identical in both scenes emphasizing that the calibration performed in the ITP is correct (at cm level). Finally, Figure 5a exhibits the mosaick of the different Change Raw DEMs and Figure $5 b$ is the mosaick of its difference w.r.t to the TanDEM-X DEM. No calibration was required before the mosaicking.

\section{Conclusion}

This paper aims to show the new developments of the TanDEM-X mission with respect to the Change DEM data acquisition and processing. This new DEM, generated from acquisitions independent to those used for the production of the global DEM, has a sufficient quality and accuracy to enable the retrieval of even small terrain changes on global scales with unprecedented resolution when comparing it to the TanDEM-X global DEM.

\section{$6 \quad$ Literature}

[1] S. Buckreuss, T. Fritz, M. Bachmann, M. Zink: "TerraSAR-X and TanDEM-X Mission Status," in European Conference on Synthetic Aperture Radar (EUSAR), 2018, pp. 1-4

[2] DLR EOC, “TanDEM-X Ground Segment - DEM Products Specification Document", Public Document TD-GS-PS-0021, Issue 3.1, 2016. Available: https://tandemx-science.dlr.de/

[3] Rizzoli, P. et al.: Generation and performance assessment of the global TanDEM-X digital elevation model. ISPRS Journal of Photogrammetry and Remote Sensing, 132, pp. 119-139, 2017

[4] Lachaise, M., Fritz, T.: Update of the Interferometric Processing Algorithms for the TanDEM-X High Resolution DEMs EUSAR 2016, pp. 550-553, 2016

[5] Huber, M-, Wessel, B., Wendleder, A. Hoffmann, J. and Roth, A.: A framework for an automated editing of TanDEM-X digital elevation models. Proceedings of IGARSS 2015, pp. 3826-2829, 2015

[6] Gonzalez C., Bachmann M., Bueso-Bello J.L:, Rizzoli P. and Zink M. : Automatic Editing of the TanDEM-X Global DEM, EUSAR 2020

[7] Gruber, A., Wessel, B., Huber, $M$ and Roth, A.: Operational TanDEM-X DEM calibration and first validation results. ISPRS Journal of Photogrammetry and Remote Sensing, 73, pp. 39-49, 2012 
(a)

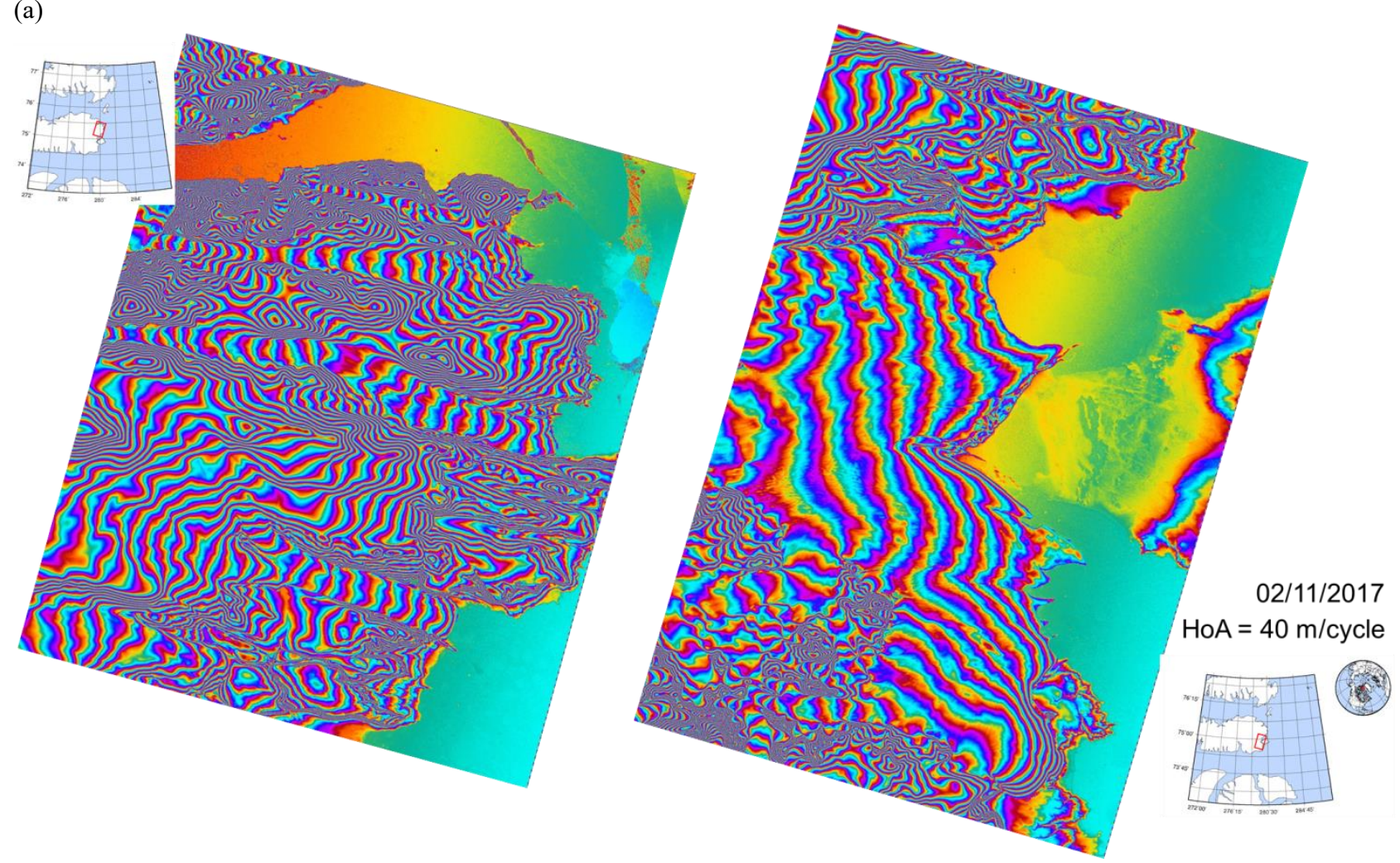

(b)

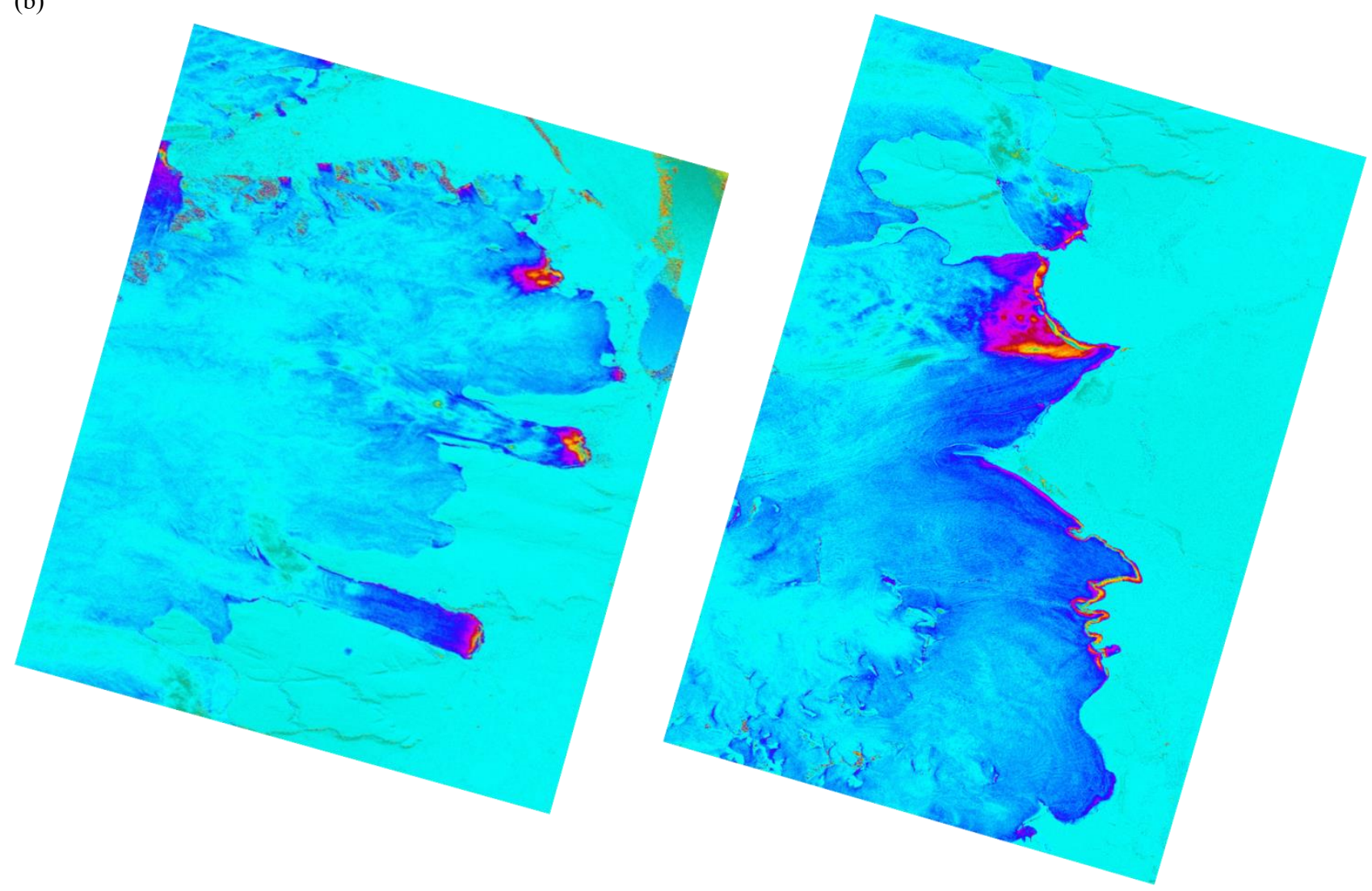

Figure 3 Two scenes from the same datatake acquired on 02/11/2017 over Devon Island (HoA=40 m/cycle). (a) interferometric phases flattened with an ellipsoid; (b) interferometric phases flattened with an edited TanDEM-X DEM. 
(c)

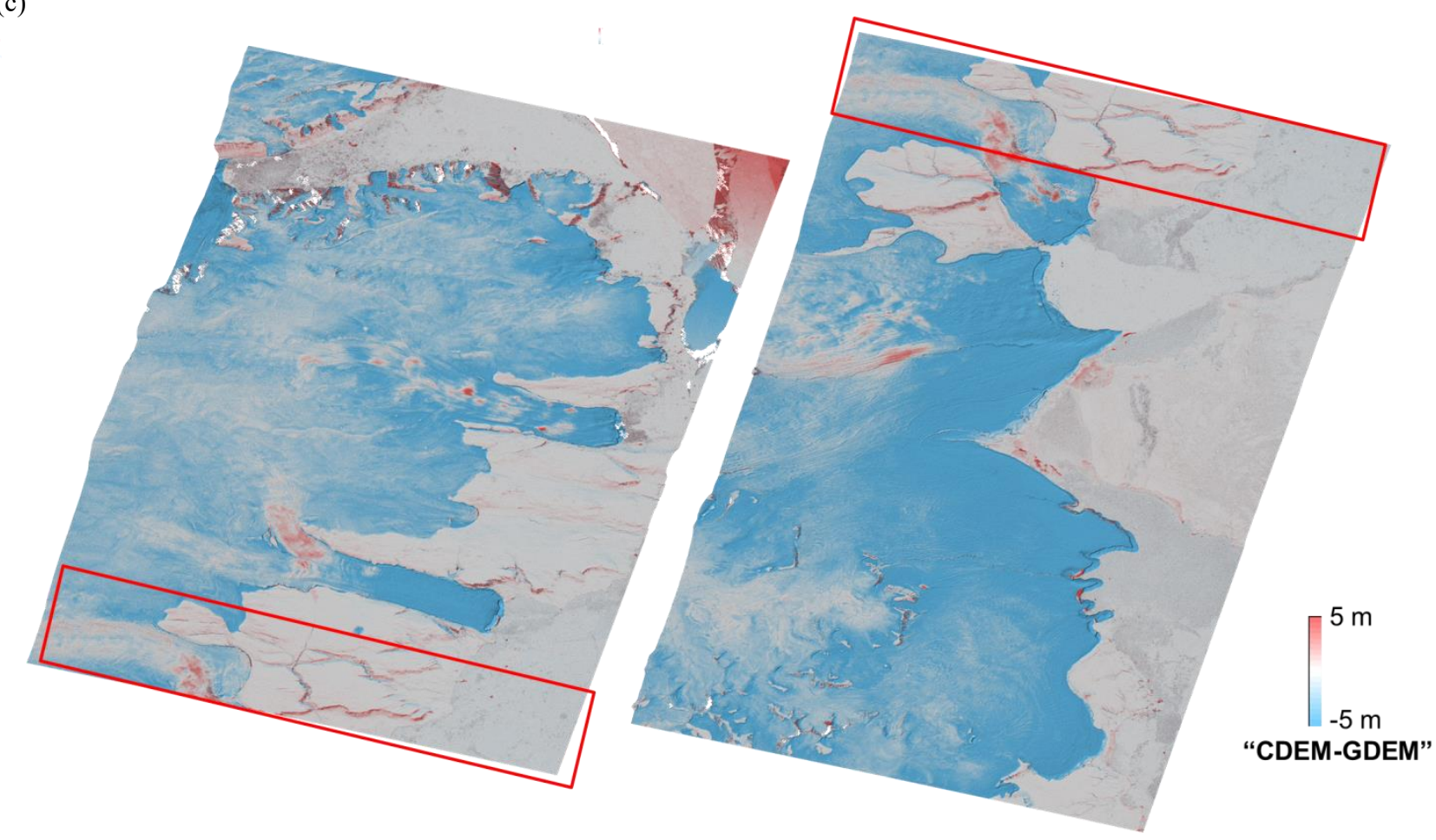

(d)

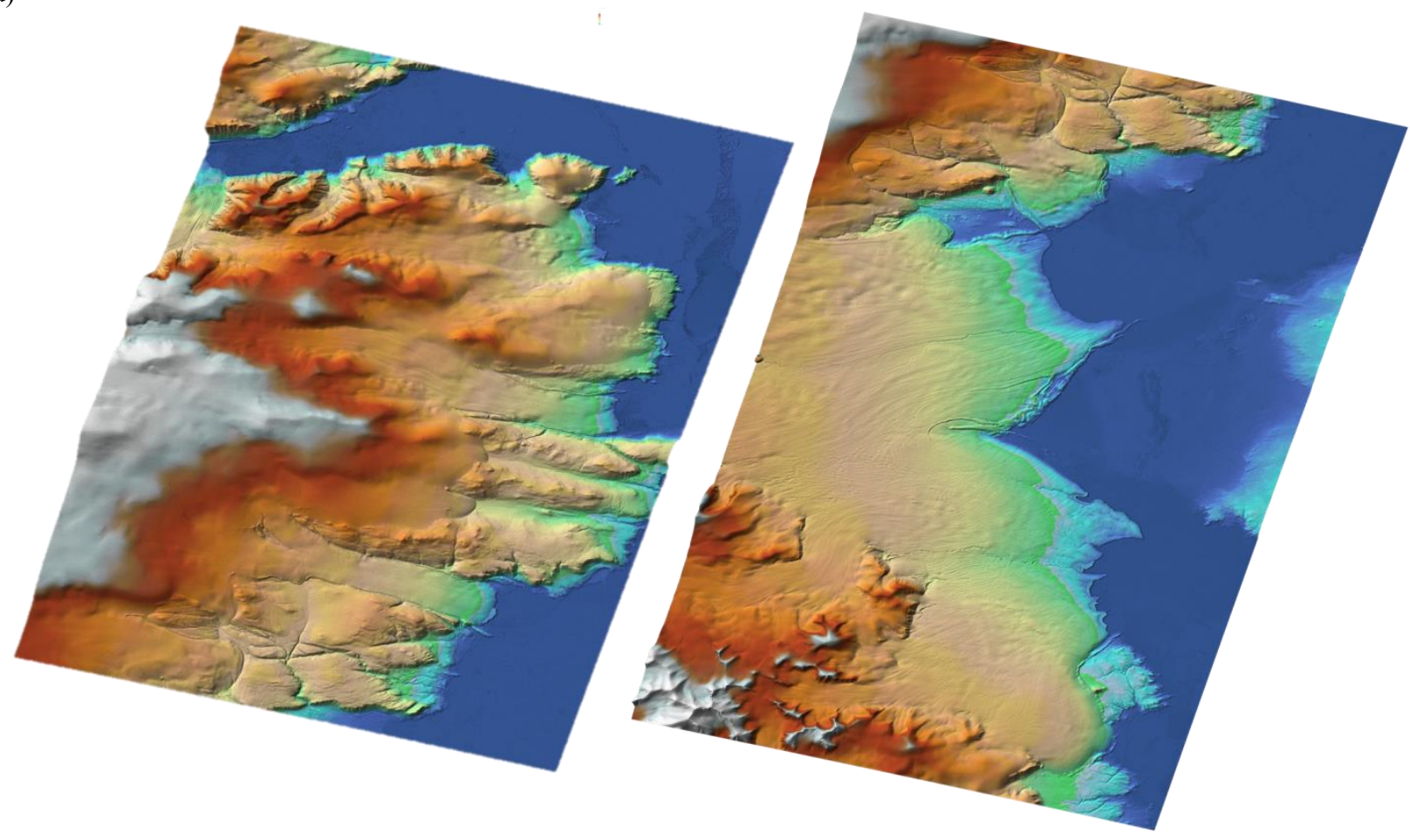

Figure 4 Two scenes from the same data take acquired on 02/11/2017 over Devon Island (HoA=40 m/cycle). (c) height differences between the new acquisition and the edited reference DEM; (d) Change Raw DEMs calibrated to the edited reference DEM 
(a)

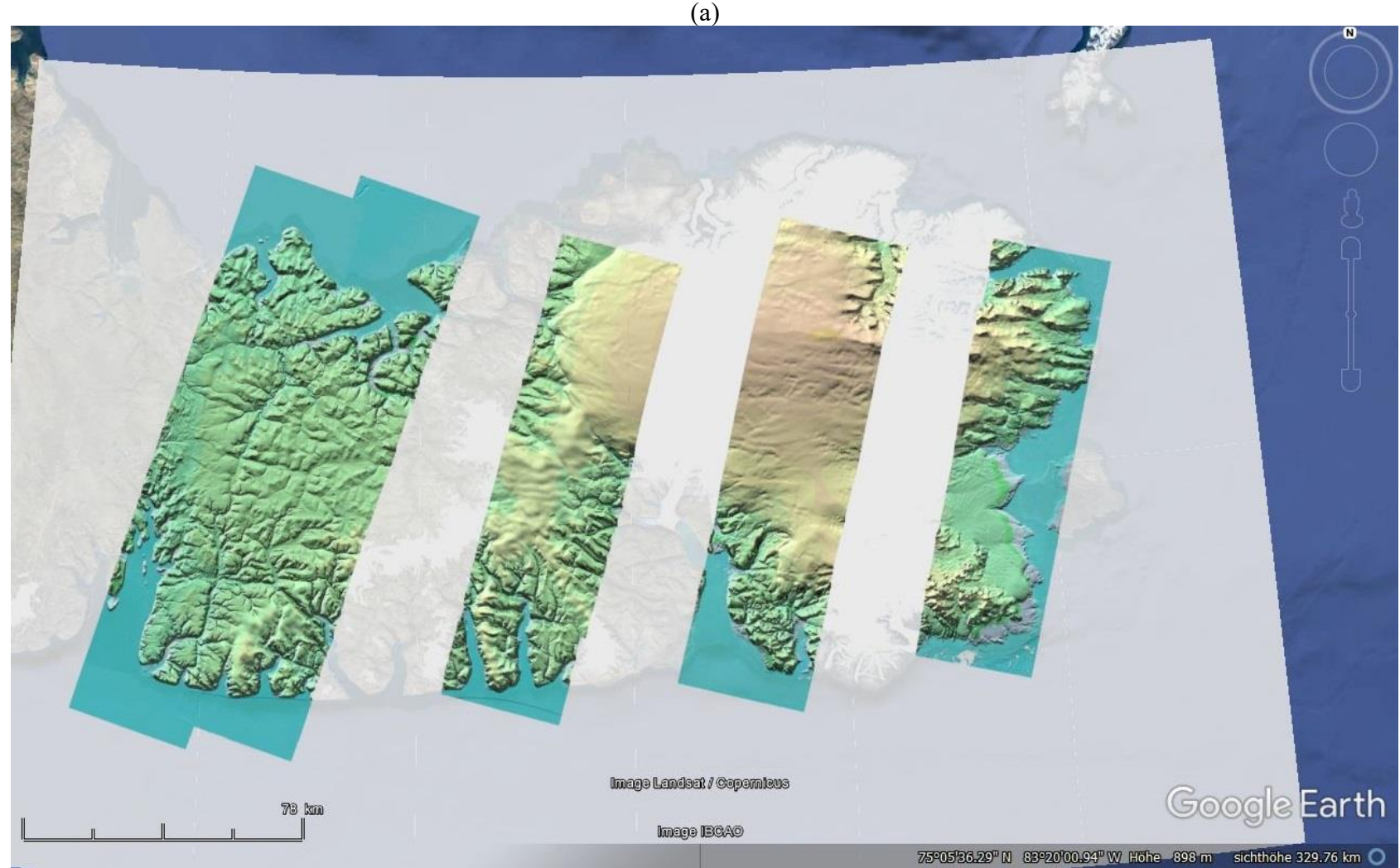

(b)

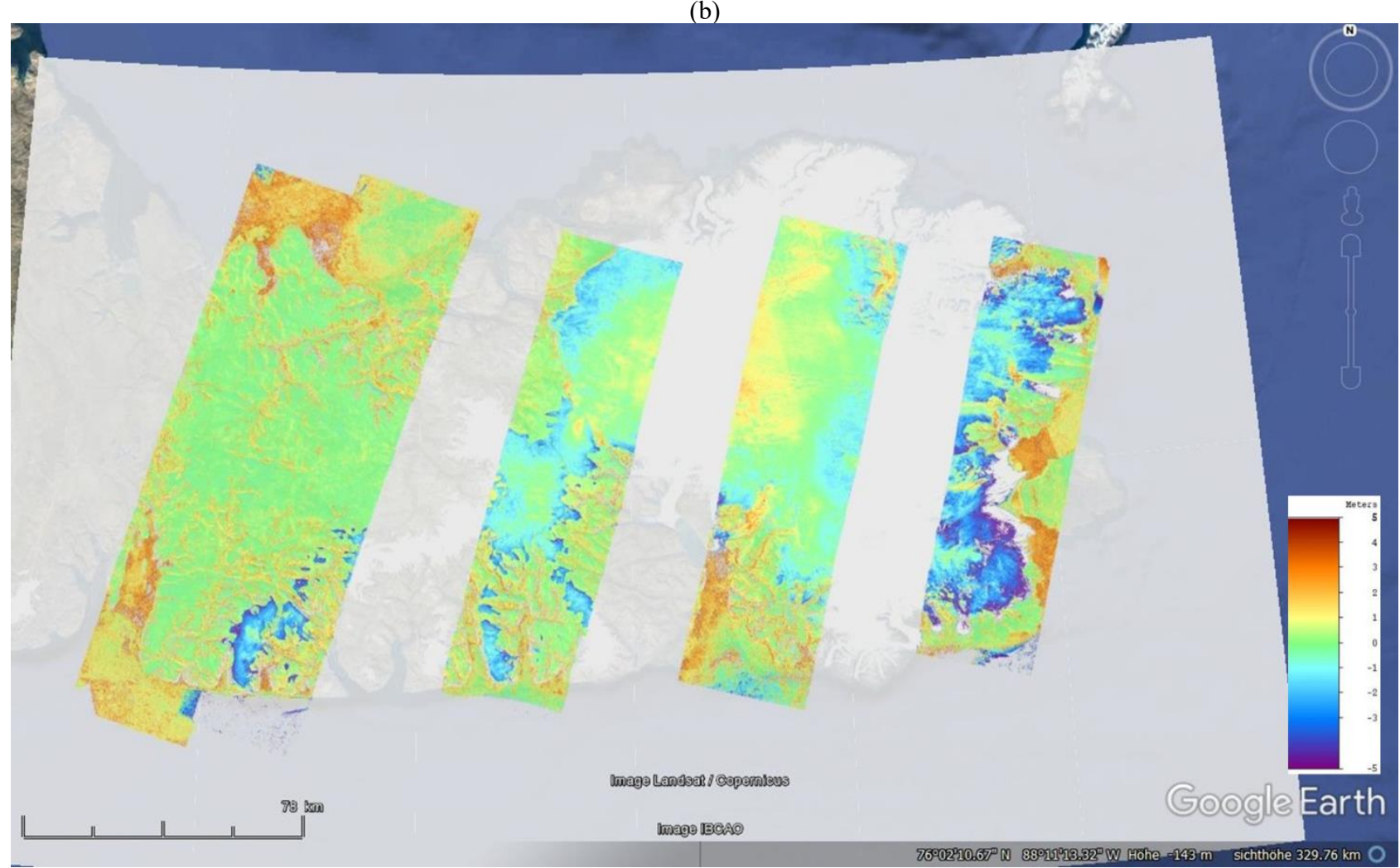

Figure 5 Devon Island mosaic. (a) mosaicked DEM of the processed Change Raw DEMs; (b) height difference with respect to TanDEM-X DEM 